\title{
Selfish Or Selfless? on the Signal Value of Emotion in Altruistic Behavior
}

Alixandra Barasch, University of Pennsylvania, USA

Deborah Small, University of Pennsylvania, USA

Emma E. Levine, University of Pennsylvania, USA

Jonathan Berman, University of Pennsylvania, USA

We examine when consumers gain credit for good deeds. Contrary to theories that decry emotions as selfish, people view emotions as authentic, and therefore deserving of charitable credit. Further, feeling good as a result of giving is viewed positively, unless someone explicitly claims to have been motivated by emotional benefits.

[to cite]:

Alixandra Barasch, Deborah Small, Emma E. Levine, and Jonathan Berman (2013),"Selfish Or Selfless? on the Signal Value of Emotion in Altruistic Behavior", in NA - Advances in Consumer Research Volume 41, eds. Simona Botti and Aparna Labroo, Duluth, MN : Association for Consumer Research.

[url]:

http://www.acrwebsite.org/volumes/1015778/volumes/v41/NA-41

\section{[copyright notice]:}

This work is copyrighted by The Association for Consumer Research. For permission to copy or use this work in whole or in part, please contact the Copyright Clearance Center at http://www.copyright.com/. 


\section{Consumers' Prosocial Motives and Decision-Making}

Chairs: Leif D. Nelson, University of California, Berkeley, USA

Minah H. Jung, University of California, Berkeley, USA

Paper \#1: Powering Up with Indirect Reciprocity in a LargeScale Field Experiment

Erez Yoeli, Federal Trade Commission, USA

Moshe Hoffman, University of California, San Diego, USA

David G. Rand, Yale University, USA

Martin A. Nowak, Harvard University, Program for

Evolutionary Dynamics, USA

Paper \#2: Signaling Virtue: Charitable Behaviors Under Consumer Elective Pricing

Minah H. Jung, University of California, Berkeley, USA

Leif D. Nelson, University of California, Berkeley, USA

Ayelet Gneezy, University of California, San Diego, USA

Uri Gneezy, University of California, San Diego, USA

Paper \#3: Benefiting from Inequity Promotes Prosociality

Yoel Inbar, Tilburg University, The Netherlands

Emily Zitek, Cornell University, USA

Alexander Jordan, Dartmouth College, USA

Paper \#4: Selfish or selfless? On the Signal Value of Emotion in Altruistic Behavior

Alixandra Barasch, University of Pennsylvania, USA

Emma E. Levine, University of Pennsylvania, USA

Jonathan Z. Berman, University of Pennsylvania, USA

Deborah A. Small, University of Pennsylvania, USA

\section{SESSION OVERVIEW}

People are motivated to care about others. This motivation often reflects their social goal to be perceived positively by others and themselves. To achieve this goal, people live their lives expressing concern toward the welfare of others and helping others who are in need. This session brings together contemporary research that examines the motives behind consumers' prosocial behaviors. Four papers portray the intricacy of consumers' prosocial motives and decision-making in varying social contexts. Yoeli, Hoffman, Rand, and Nowak examine how consumers' concerns for reputation can foster cooperation in preserving public goods. In a large-scale field experiment $(\mathrm{N}=1,408)$ in collaboration with a major electric utility company, they investigated the effect of observability in increasing participation in an energy efficiency program. Participants in the observable treatment were three times more likely to participate than those in the non-observable treatment. Observability was also four times more effective than offering a \$25 incentive. Jung, Nelson, Gneezy, and Gneezy investigate how consumers respond to an opportunity to signal their generosity under pay-what-you-want pricing in four field experiments $(\mathrm{N}=58,501)$. When people paid what they want and a portion of their payment goes to charity, they paid more but more people opted-out of engaging in the transaction entirely. Customers were sensitive to the presence of charitable signals but insensitive to the scale of charitable signals. Inbar, Zitek, and Jordan show that people's prosociality is influenced by their desire to maintain a sense of equity. Across three studies, participants who were over-rewarded subsequently acted more prosocially than those who were rewarded fairly. When participants were over-rewarded, they donated more to charity, volunteered more time for a good cause, and were more willing to help others. People are motivated to "balance out" their unearned fortune by behaving more prosocially towards the world at large. Barasch, Levine, Berman, and Small demonstrate that the strength of positive emotion towards charitable giving signals authenticity, therefore, is perceived deserving charitable credit. Participants judged a donor to be more authentically motivated when the donor felt a strong emotion from giving. However, when a donor explicitly stated a utilitarian motive or emotional benefits from giving, they were perceived to be less authentically motivated. Taken together, this session contributes to the understanding of consumers' prosocial motives. In contributing to public goods, consumers are more responsive to a reputational incentive than to a monetary reward. Consumers pay more for a product when a portion of their payment benefits charity but fewer consumers engage in such transactions. They are not sensitive to the scale of their charitable contribution. People are motivated to maintain a sense of equity and behave more prosocially when they are overly rewarded. People perceive a strong positive emotion towards charitable giving to signal an authentic motivation that deserves charitable credit.

\section{Powering Up with Indirect Reciprocity in a Large-Scale Field Experiment}

\section{EXENDED ABSTRACT}

The evolution of cooperation via indirect reciprocity has been a topic of great interest in recent years. Mathematical models and computer simulations have demonstrated the power of indirect reciprocity for promoting cooperative behavior (1-23). This body of theoretical work is supported by behavioral experiments where subjects play economic games in the laboratory. People are substantially more cooperative when their decisions are observable, and when others can respond accordingly (24-43). Subjects understand that having a good reputation is valuable in these settings (32), and so are willing to pay the cost of cooperation. Observability particularly increases cooperation when the prosocial nature of the cooperative choice is made salient $(38,44)$. Moreover, experimental evidence indicates that indirect reciprocity is deeply entrenched in human psychology: subtle cues of observability have large effects on cooperation levels (45-48), and our initial impulse to cooperate in one-shot anonymous settings is likely the result of adaptation in a world dominated by reputational concerns $(49,50)$. These laboratory experiments generate powerful insights into human psychology, and provide clear evidence for the importance of indirect reciprocity. However, they typically employ abstract economic games and involve the interaction of only a handful of subjects. Thus the question of whether observability effects large-scale cooperation in real world settings outside of the laboratory remains largely unexplored (exceptions include (5153)). The extent to which findings from theory and the lab generalize to natural field settings is of great importance, both for scientific understanding and for public policy (54). We address this question by running a large-scale field experiment on the effect of observability in a public goods game. We collaborated with a major electric utility company to enroll consumers in a "demand response" program. This program helps to prevent blackouts by reducing excessive use of air-conditioning during periods of high electricity demand. The cost of electricity production can spike hundreds-fold during demand peaks. Yet the price consumers pay is typically constant across time. Thus during peak periods there is a dramatic mismatch between price and actual cost, leading to excessive energy use. This reduces grid reliability, drives up energy costs, increases the risk of black 


\section{8 / Consumers' Prosocial Motives and Decision-Making}

outs, and harms the environment. In recent years, reducing excessive peak energy use has become a target of regulatory efforts to increase efficiency in the electricity industry. To explore the effect of observability on this real-world public goods problem, we solicited residents of 15 homeowners associations (HOAs) to participate in a demand response program. Residents who volunteered for this program allowed the utility to install a device that remotely curbs their central air-conditioners when necessary: on days with unusually high demand or in the case of an unexpected plant or transmission failure. Residents who volunteered, therefore, contributed to a public good by improving the stability of the electrical grid in all of California, at the cost of some personal inconvenience. We solicited volunteers by delivering mailers to residents and asking them to participate. Signup sheets were posted in a communal area near their home, usually by a shared mailbox kiosk. In our primary manipulation, we varied whether residents' neighbors could tell who had signed up for the program. We did so by varying whether the publicly posted sheets required residents to print their name and unit number (observable treatment) or only a code that does not reveal their identity (anonymous treatment). We find that residents in the observable treatment are nearly three times as likely to participate in the demand response program as residents in the anonymous treatment (Fraction of residents participating: anonymous $=0.030$, observable $=0.088, \mathrm{p}<$ $0.01, \mathrm{~N}=1408$ ). All statistics presented are from Probit regressions including various controls, with standard errors clustered at the HOA level; for details and regression tables, see Supporting Information (SI). The effect of the observable treatment is nearly five times that of offering a $\$ 25$ incentive (the estimated effect of the incentive is 0.009 ; a Wald test rejects that the coefficients on observability and the $\$ 25$ incentive are identical, $p=0.024$ ). The observable treatment is also more effective among populations where ongoing relationships and reputations are expected to play a larger role. Observability increased participation among those living in apartment buildings (Fraction of residents participating: anonymous $=0.048$, observable $=0.114, \mathrm{p}<0.01, \mathrm{~N}=582$ ), while it had little effect on the inhabitants of row houses or individual homes (Fraction of residents participating: anonymous $=0.024$, observable $=0.038, \mathrm{NS}, \mathrm{N}=826$; yielding an estimated interaction of $0.052, \mathrm{p}=0.04$ ). Additionally, observability dramatically increased participation among owners (Fraction of residents participating: anonymous $=0.024$, observable $=0.099, \mathrm{p}<0.01, \mathrm{~N}=1015$ ) but had little effect on renters (Fraction of residents participating: anonymous $=0.045$, observable $=$ 0.059 , NS, $\mathrm{N}=393$; yielding an estimated interaction of $0.046, \mathrm{p}<$ $0.01)$. Finally, we provide evidence that the effect of observability is unique to public goods. An additional 1005 subjects received exactly the same treatment as described above, except that the mailers they received were stripped of any language that framed the demand response program as a public good. The effect of observability was dramatically reduced in this cohort (Fraction of residents participating: anonymous $=0.061$, observable $=0.086, \mathrm{NS}, \mathrm{N}=1005$; Estimated interaction between observability and the public good message in a pooled regression is $0.035, \mathrm{p}=0.047$ ). We have shown that indirect reciprocity promotes cooperation in a real-world public goods game effecting thousands of people. Indirect reciprocity offers a powerful tool for promoting cooperation in contexts of great societal importance. Developing interventions that harness indirect reciprocity is a promising direction for future public policy initiatives.

\section{REFERENCES}

Andreoni J \& Bernheim BD (2009) Social image and the 50-50 norm: A theoretical and experimental analysis of audience effects. Econometrica 77(5):1607-1636.
Andreoni J \& Petrie R (2004) Public goods experiments without confidentiality: a glimpse.

Ashraf N, Bandiera O, \& Jack K (2012) No margin, no mission? A field experiment on incentives for pro-social tasks. Harvard Business School Working Papers.

Berger U (2011) Learning to cooperate via indirect reciprocity. Games and Economic Behavior 72(1):30-37.

Bolton GE, Katok E, \& Ockenfels A (2005) Cooperation among strangers with limited information about reputation. Journal of Public Economics 89(8): 1457-1468.

Brandt H \& Sigmund K (2006) The good, the bad and the discriminator - Errors in direct and indirect reciprocity. J. Theor. Biol. 239(2):183-194.

Burnham T \& Hare B (2007) Engineering Human Cooperation. Human Nature 18(2): 88-108.

Choi J-K \& Ahn TK (In press) Strategic reward and altruistic punishment support cooperation in a public goods game experiment. Journal of Economic Psychology (0).

Ernest-Jones M, Nettle D, \& Bateson M (2011) Effects of eye images on everyday cooperative behavior: a field experiment. Evolution and human behavior 32(3):172-178.

Fu F, Hauert C, Nowak MA, \& Wang L (2008) Reputation-based partner choice promotes cooperation in social networks. Physical Review E 78(2):026117.

Haley KJ \& Fessler DMT (2005) Nobody's watching? Subtle cues affect generosity in an anonymous economic game. Evolution and Human Behavior 26:245-256.

Iiasa L (1998) The dynamics of indirect reciprocity. J. theor. Biol 194:561-574.

Jacquet J, Hauert C, Traulsen A, \& Milinski M (2011) Shame and honour drive cooperation. Biology letters 7(6): 899-901.

Kandori M (1992) Social norms and community enforcement. Rev Econ Stud 59:63-80.

Karlan D \& McConnell MA (2012) Hey look at me: The effect of giving circles on giving. (National Bureau of Economic Research).

Kossmeier S, Ariely D, \& Bracha A (2009) Doing good or doing well? Image motivation and monetary incentives in behaving prosocially. American Economic Review 99(1): 544-555.

Lacetera N \& Macis M (2010) Social image concerns and prosocial behavior: Field evidence from a nonlinear incentive scheme. Journal of Economic Behavior \& Organization 76(2):225-237.

Leimar O \& Hammerstein P (2001) Evolution of cooperation through indirect reciprocity. Proceedings of the Royal Society of London. Series B: Biological Sciences 268(1468): 745-753.

Levitt SD \& List JA (2007) What do laboratory experiments measuring social preferences reveal about the real world? Journal of Economic Perspectives into fund-raising. Journal of Public Economics 88(7): 1605-1623.

Linardi S \& McConnell MA (2008) Volunteering and Image Concerns. CaliforniaInstitute of Technology Working Paper.

List JA, Berrens RP, Bohara AK, \& Kerkvliet J (2004) Examining the role of social isolation on stated preferences. American Economic Review:741-752.

Manapat ML \& Rand DG (2012) Delayed and Inconsistent Information and the Evolution of Trust. Dynamic Games and Applications:1-10.

Manapat ML, Nowak MA, \& Rand DG (2012) Information, irrationality and the evolution of trust. Journal of Economic Behavior and Organization. 
Masuda N \& Ohtsuki H (2007) Tag-based indirect reciprocity by incomplete social information. Proceedings of the Royal Society B: Biological Sciences 274(1610):689-695.

Milinski M, Semmann D, \& Krambeck H (2002) Donors to charity gain in both indirect reciprocity and political reputation. Proceedings of the Royal Society of London. Series B: Biological Sciences 269(1494): 881-883.

Milinski M, Semmann D, \& Krambeck HJ (2002) Reputation helps solve the 'tragedy of the commons'. Nature 415(6870): 424426.

Milinski M, Semmann D, Bakker TCM, \& Krambeck H-Jr (2001) Cooperation through indirect reciprocity: image scoring or standing strategy? Proceedings of the Royal Society of London. Series B: Biological Sciences 268(1484): 2495-2501.

Nakamura M \& Masuda N (2011) Indirect Reciprocity under Incomplete Observation. PLoS Comput Biol 7(7):e1002113.

Nowak MA \& Sigmund K (1998) Evolution of indirect reciprocity by image scoring. Nature 393(6685):573-577.

Nowak MA \& Sigmund K (2005) Evolution of indirect reciprocity. Nature 437(7063):1291-1298.

Nowak MA, Page KM, \& Sigmund K (2000) Fairness Versus Reason in the Ultimatum Game. Science 289(5485): 17731775 .

Ohtsuki H \& Iwasa Y (2004) How should we define goodness?reputation dynamics in indirect reciprocity. Journal of Theoretical Biology 231(1): 107-120.

Ohtsuki H \& Iwasa Y (2006) The leading eight: social norms that can maintain cooperation by indirect reciprocity. J Theor Biol 239(4):435-444.

Ohtsuki $H \&$ Iwasa $Y$ (2007) Global analyses of evolutionary dynamics and exhaustive search for social norms that maintain cooperation by reputation. Journal of Theoretical Biology 244(3) : 518-531.

Ohtsuki H, Iwasa Y, \& Nowak MA (2009) Indirect reciprocity provides only a narrow margin of efficiency for costly punishment. Nature 457(1):79-82.

Pacheco JM, Santos FC, \& Chalub FACC (2006) Stern-Judging: A Simple, Successful Norm Which Promotes Cooperation under Indirect Reciprocity. PLoS Comput Biol 2(12): e178.

Panchanathan K \& Boyd R (2003) A tale of two defectors: the importance of standing for evolution of indirect reciprocity. Journal of Theoretical Biology 224(1):115-126.

Panchanathan K \& Boyd R (2004) Indirect reciprocity can stabilize cooperation without the second-order free rider problem. Nature 432(7016):499-502.

Pfeiffer T, Tran L, Krumme C, \& Rand DG (2012) The value of reputation. Journal of the Royal Society Interface:doi:10.1098/ rsif.2012.0332.

Powell KL, Roberts G, \& Nettle D(2012) Eye Images Increase Charitable Donations: Evidence From an Opportunistic Field Experiment in a Supermarket. Ethology.

Rand DG, Dreber A, Ellingsen T, Fudenberg D, \& Nowak MA (2009) Positive Interactions Promote Public Cooperation. Science 325(5945):1272-1275.

Rand DG, Greene JD, \& Nowak MA (2012) Spontaneous giving and calculated greed. Nature 489(7416): 427-430.

Rege M \& Telle K (2004) The impact of social approval and framing on cooperation in public good situations. Journal of Public Economics 88(7):1625-1644.

Rockenbach B \& Milinski M (2006) The efficient interaction of indirect reciprocity and costly punishment. Nature 444(7120): 718-723.
Schulz JF, Fischbacher U, Thöni C, \& Utikal V (In press) Affect and fairness: Dictator games under cognitive load. Journal of Economic Psychology (0).

Seinen I \& Schram A (2006) Social status and group norms: Indirect reciprocity in a repeated helping experiment. European Economic Review 50(3):581-602.

Semmann D, Krambeck H-J, \& Milinski M (2005) Reputation is valuable within and outside one's own social group. Behavioral Ecology and Sociobiology 57(6): 611-616.

Suzuki S \& Akiyama E (2007) Evolution of indirect reciprocity in groups of various sizes and comparison with direct reciprocity. Journal of Theoretical Biology 245(3):539-552.

Suzuki S \& Akiyama E (2007) Three-person game facilitates indirect reciprocity under image scoring. Journal of Theoretical Biology 249(1): 93-100.

Tadelis S (2007) The power of shame and the rationality of trust. Available at SSRN 1006169.

Uchida S \& Sigmund K (2010) The competition of assessment rules for indirect reciprocity. Journal of Theoretical Biology 263(1): 13-19.

Ule A, Schram A, Riedl A, \& Cason TN (2009) Indirect Punishment and Generosity Toward Strangers. Science 326(5960): 17011704.

Wedekind C \& Braithwaite VA (2002) The Long-Term Benefits of Human Generosity in Indirect Reciprocity. Current Biology 12(12): 1012-1015.

Wedekind C \& Milinski M (2000) Cooperation Through Image Scoring in Humans. Science 288(5467): 850-852.

\section{Signaling Virtue: Charitable Behaviors under Consumer Elective Pricing}

\section{EXENDED ABSTRACT}

People want to be seen as kind, fair, and generous, and that goal influences their decision-making. Pay-what-you-want pricing highlights those goals by allowing consumers' to express their social preferences in a diagnostic transaction environment. This paper investigates how the opportunity to signal social identity influences consumer behavior under pay-what-you-want pricing.

In a large field experiment, Gneezy et al. (2012) found that when people pay-what-they-want and a portion of their payment goes to charity, they are less likely to buy, but pay substantially more when they do. The authors attribute this behavior largely to people's identity and self-image concerns. People want to pay a low price, but when a purchase looks like charitable giving, they also want to avoid looking greedy, either by paying a generous amount or simply not purchasing. These behaviors highlight two related questions. First, how important are the relative concerns for self-signaling and social signaling? Second, the logic above contrasts a quantitative concern (finding the right low price) with a qualitative one (feeling like a nice person). If that is correct, then we might expect to see high sensitivity to charitable giving, but low sensitivity to the extent of that giving. In four field experiments we manipulating the presence and magnitude of charitable signals to understand how these forces operate. In Study 1, we sold gourmet coffee at a farmers' market in California. All participants $(\mathrm{N}=18,672)$ saw a sign indicating they can pay-what-they-want for coffee and that $50 \%$ of their payment goes to a local charity. Purchasers $(\mathrm{N}=406)$ were randomly assigned to one of four payment conditions as they approached the cashier. To manipulate whether the signal was social, some people were told to pay anonymously (by placing their payment in an envelope and dropping it in a sealed box) whereas others paid the cashier directly. We also 


\section{0 / Consumers' Prosocial Motives and Decision-Making}

manipulated the value of the external signal by placing either a commercial (the coffee vendor's logo) or a charity logo on the coffee cup. Highlighting the value of self-signaling, people paid no more when paying directly than when paying anonymously $\left(M_{\text {direct }}=\$ 2.76\right.$ vs. $\left.M_{\text {anonymous }}=\$ 2.81\right)$. People paid more when they saw the charitable logo on the cups than when they saw the commercial logo $(M$ $=\$ 3.00$ vs. $M_{\text {coffeelogo }}=\$ 2.59$ ). Perhaps the charitable logo induced higher payments because people were reminded of the substantial proportion of their payment (50\%) going to charity? Would the same influence persist if a trivial proportion (e.g. 1\%) went to charity? In Study 2 we again investigated the value of the external signal of the product by manipulating the observable logo. In addition, we looked at sensitivity to the scope of the charitable signal by manipulating the amount going to charity. For this field experiment we sold reusable shopping bags in front of an organic grocery in San Francisco. As in Study 1, we manipulated a charitable vs. commercial signal by selling bags with either the grocery store logo or a local charity logo. We also manipulated what percentage of the payment would go to a local charity ( $0 \%$ vs. $1 \%$ vs. $50 \%)$. People $(\mathrm{N}=12,394)$ who entered the grocery store saw a sign indicating the randomly assigned condition. The bag logo had no effect on either purchase rate or purchase price. There was, however, a significant effect of the percentage going to charity. Replicating Gneezy et al. (2010), people were less likely to buy, but paid more, when a portion of their payment went to charity. Notably, this was true even when only $1 \%$ was going to charity; customers were significantly less likely to buy (3.65\% vs. $4.94 \%)$, but paid more for a bag compared to the strict PWYW condition $\left(M_{P W Y W}\right.$ $=\$ 2.43$ vs. $\left.M_{P W Y W+1 \% \text { to Charity }}=\$ 1.41\right)$. There were no differences in purchase rates between the $1 \%$ and $50 \%$ conditions, but customers in the $50 \%$-to-charity condition, paid a higher price. In Study 1 and 2, people approached our shop after seeing a shop sign clearly indicating it was a pay-what-you-want shop and that a portion of their payment went to charity. It is entirely likely therefore that difference in purchase prices is a pure reflection of self-selection. If we remove this selection bias, will people still show sensitivity to the proportion of charitable giving? In Study 3, we returned to the same gourmet coffee vendor as in Study 1. This time, customers $(\mathrm{N}=150)$ did not see a pay-what-you-want sign, but instead, after saying that they wanted coffee, were told that they could find out the price of coffee by drawing a piece of paper out of a box. The box contained three different types of prices: Pay-what-you-want, pay-what-you-want and $10 \%$ going to charity or pay-what-you-want and $50 \%$ going to charity. We found that when the selection bias was removed, people did not pay more for a small charity proportion $(10 \%)$ than no charity condition ( $\mathrm{M}=\$ 2.31$ vs. $\mathrm{M}=\$ 2.18)$, but they still paid more when $50 \%$ went to charity $(\mathrm{M}=\$ 3.23)$. Even though a $1 \%$ (or $10 \%$ ) contribution is financially much more similar to $0 \%$, people opt out of purchase at similar rates to the $50 \%$ contribution. Their payments show some incomplete sensitivity to the contribution percentage (Study 2 and 3). How sensitive will people be as the proportion increases? In Study 4 we sold reusable shopping bags in front of a traditional supermarket in Oakland, California. People $(\mathrm{N}=27,285)$ were randomly assigned to one of five different pay-what-you-want pricing conditions, each reflecting a different percentage going to charity ( $0 \%$ vs. $1 \%$ vs. $50 \%$ vs. $99 \%$ vs. $100 \%$ ). The first condition is pure pay-what-you-want, the latter is pure charitable giving. Signs clearly indicated the condition (randomized every 50 passersby) outside the store entrance. Again we replicated Gneezy et al. (2010): people purchased less frequently but paid significantly more when they saw the sign with a charitable proportion than when no proportion went to charity. However, the purchase rates and average payments did not differ across the four charity conditions: People were highly sensi- tive to whether or not a charity was benefiting, but almost entirely insensitive as to whether that benefit was $1 \%$ or $100 \%$. In summary, consumers exhibit varying degrees of sensitivity to social signals under pay-what-you-want pricing. This is observed in how they respond to the types of signal (charitable vs. commercial), the magnitude of the signals, and their payments. People show clear sensitivity to the qualitative social value of a purchase, but much less sensitivity to the quantitative social value of a purchase.

\section{REFERENCES}

Gneezy, A., Gneezy, U., Nelson, L. D., \& Brown, A. (2010). Shared social responsibility: A field experiment in pay-what-you-want pricing and charitable giving. Science, 329(5989), 325-327.

Gneezy, A., Gneezy, U., Riener, G., \& Nelson, L. D. (2012). Pay-what-you-want, identity, and self-signaling in markets. Proceedings of the National Academy of Sciences, 109(19), 7236-7240.

\section{Benefiting from Inequity Promotes Prosociality EXENDED ABSTRACT}

People care about fairness. In our interpersonal relationships, we strive to maintain an equitable balance of costs and benefits (Fiske, 1991), and even in economic games with strangers people are reluctant to maximize their earnings at equity's expense (Bolton, Katok, \& Zwick, 1998; Fehr \& Schmidt, 1999; Rabin, 1993). Indeed, a concern with equity may be part of our evolutionary heritage, as an inclination to return favors can confer adaptive benefits when individuals' reputations are known (Axelrod, 1984; Trivers, 1971). The central role that notions of equity play in our relations with others suggests that feeling that one has been treated inequitably should have important consequences for behavior. Indeed, feeling that one has been the victim of inequitable treatment can license people to act more selfishly. In one study, for example, people who had just unfairly been denied a bonus payment allocated themselves a larger portion of a shared payment on a hypothetical subsequent task ( $\mathrm{Zi}$ tek, Jordan, Monin, \& Leach, 2010). This research is consistent with the notion that just as people seek equity in their interpersonal relationships, they may also strive to maintain "equity with the world" (Austin \& Walster, 1975). According to this view, people expect to get what they deserve (and to deserve what they get) not just in relation to specific others, but also across different relationships. Being unfairly denied a deserved bonus therefore justifies one in "balancing the scales" by subsequently taking more from others (Zitek et al., 2010; see also Nisan, 1990, 1991). Most relevant for the current research, this perspective predicts that those who have benefited from unfair treatment - by, for example, receiving an overpayment or undeserved bonus - should subsequently act more generously, because they have received an undeserved benefit that must now be "balanced out." Some evidence supporting this hypothesis comes from a study in which people were led to believe that based on their qualifications they were either being over-paid or equitably paid for an interviewing job. When pay was hourly, the over-paid completed more interviews per hour than the equitably paid; when pay was piece-rate (i.e., per interview), the over-paid conducted fewer interviews per hour (Adams \& Rosenbaum, 1962). The authors argued that the over-paid participants were motivated to reduce the discomfort of iniquitous overpayment by working faster (in the hourly-pay condition) or more thoroughly (in the piece-rate condition). However, there is as yet no evidence that - as the equity with the world account would predict-over-rewarding leads to generalized prosocial behavior in addition to attempts to directly compensate the over-rewarding 
party. Here, we report such evidence. In three studies, we examine the effect of two different manipulations of over-rewarding on three different prosocial behaviors and consistently observe that people seek to "balance out" undeserved rewards by acting more prosocially. In Study 1, we tested the effect of over-rewarding on prosocial behavior by giving all participants the same $€ 3$ bonus, which they received in addition to the research credit that they had been promised for participating in the study. The circumstances under which they received this bonus, however, varied. Some participants were told that the reward was based on their superior performance on a lab task, some were told that the reward was distributed randomly, and a final group was told that due to a technicality they would receive the reward despite their poor performance. We expected the final group - those who had received their rewards despite supposedly poor performance - to subsequently give more generously when asked to make a charitable donation. Indeed, participants in the overrewarded condition donated more than those in the fairly-rewarded condition, and more than those in the randomly-rewarded condition. The latter two conditions did not differ significantly from each other. Study 2 used the same paradigm but omitted the randomly-rewarded condition. Conceptually replicating Study 1, participants were more willing to volunteer their time for a good cause when they had been over-rewarded rather than fairly rewarded. Finally, in Study 3 we used a different over-rewarding paradigm: participants were told that a "gender correction" would be applied to their scores (purportedly because gender was related to performance on the task). Those in the over-rewarded condition were told that without the gender correction they would not have qualified for the full reward, whereas those in the fairly-rewarded condition were told that they earned the full reward regardless of the gender correction. As in Study 1, we also included a randomly-rewarded condition. Consistent with Studies 1 and 2, over-rewarded participants were more helpful when the experimenter "accidentally" knocked a cup full of pencils off the desk at the end of the study. Across the three studies, we also tested (and ruled out) a variety of possible alternative explanations for this effect, including more positive mood (Isen \& Levin, 1972), reduced feelings of entitlement (Zitek et al., 2010), gratitude to the experimenter (Bartlett \& DeSteno, 2006; DeSteno et al., 2010), and fear of being envied (van de Ven, Zeelenberg, \& Pieters, 2010). We believe most plausible explanation for our findings is that people feel motivated to "balance out" their unearned good fortune by behaving more prosocially towards the world at large. That is, they attempt to maintain "equity with the world" (Austin \& Walster, 1975) - an equitable balance of burdens and benefits between themselves and other people in general.

\section{REFERENCES}

Adams, J. S., \& Rosenbaum, W. B. (1962). The relationship of worker productivity to cognitive dissonance about wage inequities. Journal of Applied Psychology, 46, 161-164.

Austin, W., \& Walster, E. (1975). Equity with the world: the trans-relational effects of equity and inequity. Sociometry, 38 , 474-496.

Axelrod, R. (1984). The evolution of cooperation. New York: Basic Books.

Bartlett, M. Y., \& DeSteno, D. (2006). Gratitude and prosocial behavior: helping when it costs you. Psychological Science, $17,319-325$.

Bolton, G. E., Katok, E., \& Zwick, R. (1998). Dictator game giving: rules of fairness versus acts of kindness. International Journal of Game Theory, 27, 269-299.
DeSteno, D., Bartlett, M., Baumann, J., Williams, L., \& Dickens, L. (2010). Gratitude as moral sentiment: Emotion-guided cooperation in economic exchange. Emotion, 10, 289-293.

Fehr, E., \& Schmidt, K. M. (1999). A theory of fairness, competition and cooperation. Quarterly Journal of Economics, 114, 817-868.

Fiske, A. P. (1991). Structures of social life. New York: Free Press.

Isen, A. M., \& Levin, P. F. (1972). Effect of feeling good on helping: Cookies and kindness. Journal of Personality and Social Psychology, 21, 384-388.

Nisan, Mordecai (1990), "Moral Balance: A Model of How People Arrive at Moral Decisions," in The Moral Domain, ed. Thomas Wren, Cambridge, MA: MIT Press, 283-314.

Nisan, Mordecai (1991), "The Moral Balance Model: Theory and Research Extending Our Understanding of Moral Choice and Deviation," in Handbook of Moral Behavior and Development, Vol. 3, ed. William M. Kurtines and Jacob L. Gerwitz, Hillsdale, NJ: Lawrence Erlbaum, 213-49.

Rabin, M. (1993). Incorporating fairness into game theory and economics. American Economic Review, 83, 1281-1302.

Trivers, R. L. (1971). The evolution of reciprocal altruism. Quarterly Review of Biology, 46, 35-57.

Van de Ven, N., Zeelenberg, M., \& Pieters, R. (2010). Warding off the evil eye: When the fear of envy increases prosocial behavior. Psychological Science, 21, 1671-1677.

Zitek E. M., Jordan A. H., Monin B., \& Leach F. R. (2010). Victim entitlement to behave selfishly. Journal of Personality and Social Psychology, 98, 245-255.

\section{Selfish or Selfless? On the Signal Value of Emotion in Altruistic Behavior}

\section{EXENDED ABSTRACT}

Emotions are both a motivating force and a consequence of consumer prosocial behavior. The debate over whether people are truly altruistic has often focused on the direction of emotion that someone feels when engaging in prosocial behavior. While some argue that the emotions people feel can genuinely involve empathic concern (e.g. Batson 1987), others argue that emotion-driven prosocial behavior is at odds with altruism because emotional actors reap intrapsychic rewards, such as a boost in positive affect (Andreoni 1990), or a reduction in negative affect (Cialdini, Darby, and Vincent 1973).

In the current research, we find that naïve theories run counter to theories that decry emotions as selfish. We predict that because emotions are perceived as spontaneous and natural (Tiedens 2001) and reflective of an actor's true motives (Ames and Johar 2009), expressing emotion in the context of prosocial behavior signals information about a consumer's true character. Our results demonstrate that lay people view emotion as reflecting genuine altruism despite recognizing that those who feel good about doing good reap intrapsychic rewards.

In Study 1, participants were asked to evaluate the survey responses of a fictitious donor who had supposedly given to the African Children's Fund. The donor filled out a post-donation survey that included his answer to the following question: "When you think about children in Africa, how emotional do you feel?" Participants were randomly assigned to view one survey that had one of the five possible responses to that question (not at all emotional, slightly emotional, moderately emotional, very emotional, or extremely emotional). Participants then rated the donor on a 12-item Charitable Credit scale (altruistic, moral, sincere, etc.), a 6-item Authentic Prosocial Motivation scale (e.g., "The donor sincerely cares about 


\section{2 / Consumers' Prosocial Motives and Decision-Making}

children in Africa,"), and a 2-item Emotional Benefits scale (e.g., "How much will donating improve the donor's mood?"). All $\alpha$ 's > .7.

Regression results demonstrate that the more emotional the donor felt, the more participants granted him charitable credit $(\beta=.34$, $t(211)=5.19, p<.001)$, the more he was judged as authentically motivated $(\beta=.31, t(211)=4.72, p<.001)$, and the more he was thought to reap emotional benefits from donating_ $(\beta=.35, t(211)=$ $5.45, p<.001)$. Thus, the signal of emotional benefits did not lead to any discounting of charitable credit.

In Study 2, we examine whether reason-based motives can substitute for emotion by comparing emotional donors to those motivated by utilitarian concerns. In Study 2, the post-donation survey included the additional question: "Please tell us more about why you donated." Participants were randomly assigned to one of three conditions. In the emotion condition, the donor checked "very emotional." In the no-emotion condition, the donor checked "not at all emotional." Finally, in the no-emotion-utilitarian condition, the donor checked "not at all emotional," but responded to the question with: "I donated because I wanted to help as many people as possible."

Consistent with our predictions, we find a significant effect of emotion condition on charitable credit, authentic prosocial motivation, and emotional benefits (all $F$ 's $>17, p$ 's $<.001$ ). Participants viewed the donor as significantly more charitable in the emotion condition compared to the no-emotion condition and no-emotion-utilitarian condition. Participants also viewed the donor as more charitable in the no-emotion-utilitarian condition than the no-emotion condition. This pattern of results also held for measures of authentic prosocial motivation and emotional benefits. These results show that reason does not substitute for emotion. Once again, participants in the emotion condition were given the most credit, despite being perceived as reaping intrapsychic benefits from giving.

In Study 3, we directly manipulate emotional benefits by manipulating how happy the donor felt after their donation. Specifically, on the fictitious survey, donors responded to the question, "How much did donating make you feel happy?" We also replaced the African Children's Fund with Nothing But Nets (an organization which distributes mosquito nets to families in Africa) to examine robustness across charities. In addition, we investigate whether or not charitable credit is conferred upon donors who describe their motivation for doing good explicitly in terms of emotional benefits to the self. Participants were assigned to one of three conditions: no-emotion, emotion, and emotion-benefits-motive. In the no-emotion condition, the donor checked "not at all" while in the emotion and the emotion-benefitsmotive conditions, the donor checked "very". Finally, when asked about why they donated, in the emotion-benefits-motive condition the donor wrote, "I donated because I wanted to feel better."

Consistent with our predictions, we find a significant effect of emotion condition on charitable credit, authentic prosocial motiva- tion, and emotional benefits (all $F$ 's $>14, p$ 's $<.001$ ). Participants viewed the donor as significantly more charitable in the emotion condition compared to the no-emotion and emotion-benefits-motive condition. There was no difference in charitable credit between the noemotion condition and the emotion-benefits-motive condition. This pattern of results also held for authentic prosocial motivation, except that the emotion-benefits-motive condition was seen as less authentic than the no-emotion condition. In other words, feeling happy as a result of donating led to increased credit, unless a donor explicitly stated that they donated in order to feel happier.

In all studies, we predicted that authentic prosocial motivation would mediate the effect of emotion level on charitable credit. Using bootstrap analyses, we find a significant indirect effect across all studies, suggesting that emotional donors were given the most credit because they were seen as having a more authentic motivation to donate to charity.

The present research offers novel insights into psychological lay theories of prosocial consumer behavior. Whereas people are often suspicious and discount charitable credit if they suspect a selfish motive, emotion fails to elicit suspicion even when the consumer attains hedonic benefits. Moreover, by articulating the mediating role of authenticity in evaluations of moral character, our findings provide a deeper understanding of how others make attributions about traits from behaviors.

\section{REFERENCES}

Ames, D. R., \& Johar, G. V. (2009), 'I'll Know What You're Like When I See How You Feel How and When Affective Displays Influence Behavior-Based Impressions," Psychological Science, 20, 586-593.

Andreoni, J. (1990), "Impure altruism and donations to public goods: a theory of warm-glow giving," The Economic Journal, 100, 464-477.

Batson, C. D. (1987), "Prosocial motivation: Is it ever truly altruistic?" In L. Berkowitz (Ed.), Advances in experimental social psychology (Vol. 20, pp. 65-122). New York: Academic Press.

Cialdini, R. B., Darby, B. L., \& Vincent, J. E. (1973), "Transgression and altruism: A case for hedonism," Journal of Experimental Social Psychology, 9, 502-516.

Tiedens, L. Z. (2001), "Anger and advancement versus sadness and subjugation: the effect of negative emotion expressions on social status conferral," Journal of Personality and Social Psychology, 80, 86-94. 